Прилози, Одд. май. йех. науки, МАНУ, ХXIX, 1-2 (2008), стр. 7-35

Contributions, Sec. Math. Tech. Sci., MANU, XXIX, 1-2 (2008), pp. 7-35

ISSN 0351-3246

UDC: 517.968

\title{
AN ELEMENTARY AND INTRODUCTORY APPROACH TO FRACTIONAL CALCULUS AND ITS APPLICATIONS
}

\author{
Hari M. Srivastava
}

\begin{abstract}
A b stract: The subject of fractional calculus (that is, calculus of integrals and derivatives of any arbitrary real or complex order) has gained considerable popularity and importance during the past three decades or so, due mainly to its demonstrated applications in numerous seemingly diverse and widespread fields of science and engineering. It does indeed provide several potentially useful tools for solving differential and integral equations, and various other problems involving special functions of mathematical physics as well as their extensions and generalizations in one and more variables. The main object of this paper ${ }^{*}$ is to present a brief elementary and introductory approach to the theory of fractional calculus and its applications especially in developing solutions of certain interesting families of ordinary and partial fractional differintegral equations. Relevant connections of some of the results presented in this lecture with those obtained in many other earlier works on this subject will also be indicated.
\end{abstract}

Key words and phrases: Fractional calculus, differential equations; integral equations; differintegral equations; special functions; mathematical physics; Fuchsian and non-Fuchsian differential equations

2000 Mathematics Subject Classification. Primary 26A33, 33B15, 34A05, 33C05; Secondary 33C20, 34A25

The paper is based on the introductory lecture given by Prof. Srivastava on the occasion of his election as a foreign member of the Macedonian Academy of Sciences and Arts. 


\section{INTRODUCTION AND A BRIEF HISTORICAL SURVEY}

The concept of it fractional calculus that is, calculus of integrals and derivatives of any arbitrary real or complex order) seems to have stemmed from a question raised in the year 1695 by Marquis de l'Hôpital (1661-1704) to Gottfried Wilhelm Leibniz (1646-1716), which sought the meaning of Leibniz's (currently popular) notation

$$
\frac{d^{n} y}{d x^{n}}
$$

for the derivative of order $n \in \mathbb{N}_{0}:=\{0,1,2, \ldots\}$ when $n=\frac{1}{2}$ (What if $n=\frac{1}{2}$ ? In his reply, dated 30 September 1695, Leibniz wrote to l'Hôpital as follows:

„... This is an apparent paradox from which, one day, useful consequences will be drawn. ...“

Subsequent mention of fractional derivatives was made, in some context or the other, by (for example) Euler in 1730, Lagrange in 1772, Laplace in 1812, Lacroix in 1819, Fourier in 1822, Liouville in 1832, Riemann in 1847 , Greer in 1859, Holmgren in 1865, Grünwald in 1867, Letnikov in 1868, Laurent in 1884, Nekrassov in 1888, Krug in 1890, and Weyl in 1917. In fact, in his 700-page textbook, entitled „Traité du Calcul Différentiel et du Calcul Intégral' (Second edition; Courcier, Paris, 1819), S. F. Lacroix devoted two pages (pp. 409-410) to fractional calculus, showing eventually that

$$
\frac{d^{\frac{1}{2}}}{d v^{\frac{1}{2}}} v=\frac{2 \sqrt{v}}{\sqrt{\pi}} .
$$

In addition, of course, to the theories of differential, integral, and integro-differential equations, and special functions of mathematical physics as well as their extensions and generalizations in one and more variables, some of the areas of present-day applications of fractional calculus include

1. Fluid Flow

2. Rheology

3. Dynamical Processes in Self-Similar and Porous Structures

4. Diffusive Transport Akin to Diffusion

5. Electrical Networks 
6. Probability and Statistics

7. Control Theory of Dynamical Systems

8. Viscoelasticity

9. Electrochemistry of Corrosion

10. Chemical Physics

end so on (see, for details, [11], [41], and [14].

The first work, devoted exclusively to the subject of fractional calculus, is the book by Oldham and Spanier [39]. One of the most recent works on the subject of fractional calculus is the book by Podlubny [41]. The latest (but certainly not the last) works on the subject of fractional calculus and its applications are the volume edited by Hilfer [11] and the monograph emphasizing upon the theory and applications of fractional differential equations by Kilbas et al. [14]. Indeed, in the meantime, numerous other works (books, edited volumes, and conference proceedings) have also appeared (see, e. g., [13], [15], [26], [27], [28], [29], [31], [30], [43], [44], [47], [48] and [55]). And today there exist at least two international journals which are devoted almost entirely to the subject of fractional calculus: (i) Journal of Fractional Calculus and (ii) Fractional Calculus and Applied Analysis.

Here, in this expository lecture, we aim at presenting an elementary and introductory overview of the theory of fractional calculus and of some of its applications.

\section{THE RIEMANN-LIOUVILLE AND WEYL OPERATORS OF FRACTIONAL CALCULUS}

Now we begin by defining the linear integral operators mathcal $I$ and K by

$$
(\text { If })(x):=\int_{0}^{x} f(t) d t
$$

and

$$
(\mathcal{K} f)(x):=\int_{X}^{\infty} f(t) d t,
$$

respectively. Then it is easily seen by iteration (and the principle of mathematical induction) that

$$
\left(I^{n} f\right)(x)=\frac{1}{(n-1) !} \int_{0}^{x}(x-t)^{n-1} f(t) d t \quad(n \in \mathbb{N})
$$

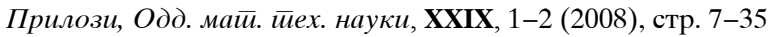


and

$$
\left(\mathcal{K}^{n} f\right)(x)=\frac{1}{(n-1) !} \int_{0}^{\infty}(x-t)^{n-1} f(t) d t \quad(n \in \mathbb{N})
$$

where, just as elsewhere in this presentation,

$$
\mathbb{N}:=\{1,2,3, \ldots\}=\mathbb{N}_{0} \backslash\{0\} .
$$

With a view to interpolating $(n-1)$ between the positive integer values of $n$, one can set

$$
(n-1) !=\Gamma(n)
$$

in terms of the familiar Gamma function. Thus, in general, Equations (2.3) and (2.4) would lead us eventually to the familiar Riemann-Liouville operator $\mathcal{R}^{\mu}$ and the Weyl operator $\mathcal{W}^{\mu}$ of fractional integral of order $\mu(\mu \in C)$, defined by (cf., e.g., Erdélyi et al. [6. Chapter 13])

$$
\left(\mathcal{R}^{\mu} f\right)(x):=\frac{1}{\Gamma(\mu)} \int_{0}^{x}(x-t)^{\mu-1} f(t) d t \quad(\mathcal{R}(\mu)>0)
$$

and

$$
\left(\mathcal{W}^{\mu} f\right)(x):=\frac{1}{\Gamma(\mu)} \int_{0}^{\infty}(t-x)^{\mu-1} f(t) d t \quad(\Re(\mu)>0)
$$

... respectively, it being tacitly assumed that the function $f(t)$ is so constrained that the integrals in (2.6) and (2.7) exist.

In the remarkably vast literature on fractional calculus and its fairly widespread applications, there are potentially useful operators of fractional derivatives $\mathcal{D}_{X ; 0}^{\mu}$ and $\mathcal{D}_{X ; \infty}^{\mu}$ of order $\mu(\mu \in \mathbb{C})$, which correspond to the abovedefined fractional integral operators $\mathcal{R}^{\mu}$ and $W^{\mu}$, respectively, and we have

$$
\begin{aligned}
& \left(\mathcal{D}_{x ; 0}^{\mu} f\right)(x):=\frac{d^{m}}{d x^{m}}\left(R^{m-\mu} f\right)(x) \\
& (m-1) \leq \mathfrak{R}(\mu)<m ; \quad m \in \mathbb{N})
\end{aligned}
$$


and

$$
\begin{gathered}
\left(\mathcal{D}_{x ; \infty}^{\mu} f\right)(x):=\frac{d^{m}}{d x^{m}}\left(\mathcal{W}^{m-\mu} f\right)(x) \\
(m-1) \leq \mathfrak{R}(\mu)<m ; \quad m \in \mathbb{N})
\end{gathered}
$$

There also exist, in the considerably extensive literature on the theory and applications of fractional calculus, numerous further extensions and generalizations of the operators $\mathcal{R}^{\mu}$ and $\mathcal{W}^{\mu}, \mathcal{D}_{x ; 0}^{\mu}$, and $\mathcal{D}_{x ; \infty}^{\mu}$, each of which we have chosen to introduce here for the sake of the non-specialists in this subject.

\section{INITIAL-VALUE PROBLEMS BASED UPON FRACTIONAL CALCULUS}

If we define, as usual, the Laplace transform operator $\mathcal{L}$ by

$$
\mathcal{L}\{f(t): s\}:=\int_{0}^{x} e^{-s t} f(t) d t=: F(s)
$$

provided that the integral exists, for the Riemann-Liouville fractional derivative operator $\mathcal{D}_{t ; 0}^{\mu}$ of order $\mu$, we have

$$
\begin{aligned}
& \mathcal{L}\left\{\left(\mathcal{D}_{t ; 0}^{\mu}, f\right)(t): s\right\}=s^{\mu} F(s)-\left.\sum_{k=0}^{n-1} s^{k}\left(\mathcal{D}_{t ; 0}^{\mu-k-1}\right) f(t)\right|_{t=0} \\
&(n-1 \leqq \Re(\mu)<n ; \quad n \in \mathbb{N})
\end{aligned}
$$

Such initial values as those occurring in (3.2) are usually not interpretable physically in a given initial-value problem. This situation is overcome at least partially by making use of the so-called Caputo fractional derivative which arose in several important works, dated 1969 onwards, by M. Caputo (see, for details, [41, p. 78 et seq.]; see also [14, p. 90 et seq.]).

In many recent works, especially in the theory of viscoelasticity and in hereditary solid mechanics, the following (Caputo's) definition is adopted for the fractional derivative of order $\alpha>0$ of a causal function $(t)$ (i.e., $(t)=0$ for $t<0)$ : 


$$
\frac{d^{\alpha}}{d t^{\alpha}} f(t):= \begin{cases}f^{(n)}(t) & \left(\alpha=n \in \mathbb{N}_{0}\right) \\ \frac{1}{\Gamma(n-\alpha)} \int_{0}^{t} \frac{f^{(n)}(\mathcal{T})}{(t-\mathcal{T})^{\alpha-n+1}} d \mathcal{T} & \left(\alpha-1<\alpha<n ; \quad \in \mathbb{N}_{0}\right)\end{cases}
$$

where $f^{(n)}(t)$ denotes the usual (ordinary) derivative of order $n$ and $\Gamma$ is the Gamma function occurring already in (2.4) and (2.5). One can apply the above notion in order to generalize some basic topics of classical mathematical physics, which are treated by simple, linear, ordinary or partial, differential equations, since [cf. Equation (3.2) and Definition (3.3)]

$$
\mathcal{L}\left\{\frac{d^{\alpha}}{d t^{\alpha}} f(t): s\right\}=s^{\alpha} F(s)-\sum_{k=0}^{n-1} s^{\alpha-k-1} f^{(k)}(0+)
$$

which obviously is more suited for initial-value problems than (3.2). See, for details, Gorenflo et al. [9], Podlubny [41] and Kilbas et al. [14].

The basic processes of relaxation, diffusion, oscillations, and wave propagation have been generalized by several authors by introducing fractional derivatives in the governing (ordinary or partial) differential equations. This leads to superslow or intermediate processes that, in mathematical physics, we may refer to as fractional phenomena. Our analysis of each of these phenomena, carried out by means of fractional calculus and Laplace transforms, leads to certain special functions in one variable of Mittag-Leffler and Fox-Wright types. These useful special functions are investigated systematically as relevant cases of the general class of functions which are popularly known as Fox's $H$ function after Charles Fox (1897-1977) who initiated a detailed study of these functions as symmetrical Fourier kernels [see, for details, Srivastava et al. [51] and [52].

We choose to summarize below some recent investigations by Gorenflo et al. [9] who did indeed make references to numerous earlier closely-related works on this subject.

\section{The Fractional (Relaxation-Oscillation) Ordinary Differential Equation}

$$
\begin{gathered}
\frac{d^{\alpha} u}{d t^{\alpha}}+c^{\alpha} u(t ; \alpha)=0 \\
(c>0 ; \quad 0<\alpha \leqq 2)
\end{gathered}
$$




\section{Case I.1: Fractional Relaxation $\quad(0<\alpha \leq 1)$}

$$
\text { Initial Condition: } \quad u(0+; \alpha)=u_{0}
$$

\section{Case I.2: Fractional Oscillation $\quad(1<\alpha \leq 2)$}

$$
\begin{array}{ll} 
& u(0+; \alpha)=u_{0} \\
& \dot{u}(0+; \alpha)=v_{0}
\end{array}
$$

with $v_{0} \equiv 0$ for continuous dependence of the solution on the parameter $\alpha$ also in the transition from $\alpha=1-$ to $\alpha=1+$.

Explicit Solution (in both cases):

$$
u(t ; \alpha)=u_{0} E_{\alpha}\left(-(c t)^{\alpha}\right),
$$

where $E_{\alpha}(z)$ denotes the familiar Mittag-Leffler function defined by (cf., e.g., Srivastava and Kashyap [52, p. 42, Equation II. 5 (23)])

$$
\begin{gathered}
E_{\alpha}(z):=\sum_{n=0}^{\infty} \frac{z^{n}}{\Gamma(\alpha n+1)}=\frac{1}{2 \pi i} \int_{-\infty}^{(0+)} \frac{\zeta^{\alpha-1} e^{\zeta}}{\zeta^{\alpha}-z} d \zeta \\
(\alpha>0 ; \quad z \in \mathbb{C})
\end{gathered}
$$

\section{The Fractional (Diffusion-Wave) Partial Differential Equation}

$$
\begin{gathered}
\frac{\partial^{2 \beta} u}{\partial t^{2 \beta}}=k \frac{\partial^{2} u}{\partial x^{2}} \\
(k>0 ; \quad-\infty<x<\infty ; \quad 0<\beta \leqq 1),
\end{gathered}
$$

where $u=u(x, t ; \beta)$ is assumed to be a causal function of time $(t>0)$ with

$$
u(\mp \infty, t ; \beta)=0 .
$$

Case II.1: Fractional Diffusion $\left(0<\beta \leq \frac{1}{2}\right)$

$$
\text { Initial Condition: } \quad u(x, 0+; \beta)=f(x)
$$

Case II.2: Fractional Wave $\quad\left(\frac{1}{2}<\beta \leqq 1\right)$

Initial Conditions: $\quad u(x, 0+; \beta)=f(x)$

$$
\dot{u}(x, 0+; \beta)=g(x)
$$


with $\mathrm{g}(\mathrm{x}) \equiv 0$ for continuous dependence of the solution on the parameter $\beta$ also in the transition from $\beta=\frac{1}{2}$ - to $\beta=\frac{1}{2}+$.

Explicit Solution (in both cases:)

$$
u(x, t ; \beta)=\int_{-\infty}^{\infty} G_{C}(\xi, t ; \beta) f(x-\xi) d \xi
$$

where the Green function $\mathcal{G}_{C}(x, t ; \beta)$ is given by

$$
|x| G_{C}(x, t ; \beta)=\frac{z}{2} \sum_{n=0}^{\infty} \frac{(-z)^{n}}{n ! \Gamma(1-\beta-\beta n)} \quad\left(z=\frac{|x|}{\sqrt{k t^{\beta}}} ; 0<\beta<1\right),
$$

which can readily be expressed in terms of Wright's (generalized Bessel) function $J_{v}^{\mu}(z)$ defined by (cf., e.g., Srivastava and Kashyap [52, p. 42, Equation II.5(22)])

$$
J_{v}^{\mu}(z):=\sum_{n=0}^{\infty} \frac{(-z)^{n}}{n ! \Gamma(1-v-\mu n)} .
$$

\section{FRACTIONAL DIFFERINTEGRAL OPERATORS BASED UPON THE CAUCHY-GOURSAT INTEGRAL FORMULA}

Operators of fractional differintegrals (that is, fractional derivatives and fractional integrals), which are based essentially upon the familiar CauchyGoursat integral formula, were considered by (among others) Sonin in 1869, Letnikov in 1868 onwards, and Laurent in 1884. In recent years, many authors have demonstrated the usefulness of fractional calculus operators (based upon the Cauchy-Goursat integral formula) in obtaining particular solutions of numerous families of homogeneous (as well as nonhomogeneous) linear ordinary and partial differential equations which are associated, for example, with many of the following celebrated equations as well as their close relatives:

\section{The Gauss Equation:}

$$
z(1-z) \frac{d^{2} w}{d z^{2}}+[\gamma-(\alpha+\beta+1) z] \frac{d w}{d z}-\alpha \beta w=0
$$




\section{The Kummer Equation:}

$$
z \frac{d^{2} w}{d z^{2}}+(\gamma-z) \frac{d w}{d z}-\alpha w=0
$$

\section{The Euler Equation:}

$$
z^{2} \frac{d^{2} w}{d z^{2}}+z \frac{d w}{d z}-\rho^{2} w=0
$$

\section{The Coulomb Equation:}

$$
z \frac{d^{2} w}{d z^{2}}+(2 \lambda-z) \frac{d w}{d z}+(\mu-\lambda)=0
$$

\section{The Laguerre-Sonin Equation:}

$$
z \frac{d^{2} w}{d z^{2}}+(\alpha+1-z) \frac{d w}{d z}+\lambda w=0
$$

\section{The Chebyshev Equation:}

$$
\left(1-z^{2}\right) \frac{d^{2} w}{d z^{2}}-z \frac{d w}{d z}+\lambda^{2} w=0
$$

\section{The Weber-Hermite Equation:}

$$
\frac{d^{2} w}{d z^{2}}-2 z \frac{d w}{d z}+(\lambda-1) w=0
$$

Numerous earlier contributions on fractional calculus along the aforementioned lines are reproduced, with proper credits, in the works of Nishimoto (cf. [29] and [31]). Moreover, a rather systematic analysis (including interconnections) of many of the results involving (homogeneous or nonhomogeneous) linear differential equations associated with (for example) the Gauss hypergeometric equation (4.1) can be found in the works of Nishimoto et al. ([37] and [38]) and the recent contribution on this subject by Wang et al. [63] (see also some other recent applications considered by Lin et al. [19] and Prieto et al. [42]). 
In the cases of (ordinary as well as partial) differential equations of higher orders, which have stemmed naturally from the Gauss hypergeometric equation (4.1) and its many relatives and extensions, including some of the above-listed linear differential equations (4.2) to (4.7), there have been several seemingly independent attempts to present a remarkably large number of scattered results in a unified manner. We choose to furnish here the generalizations (and unifications) proposed in one of the latest works on this subject by Tu et al. [59] in which references to many earlier related works can be found. We find it to be convenient to begin by recalling the following definition of a fractional differintegral (that is, fractional derivative and fractional integral) of $f(z)$ of order $v \in \mathbb{R}$.

Definition (cf. [29], [31], and [57]). If the function $f(z)$ is analytic and has no branch point inside and on $C$, where

$$
C:=\left\{C^{-}, C^{+}\right\} \text {, }
$$

$C^{-}$is a contour along the cut joining the points $z$ and $-\infty+i \Im(z)$, which starts from the point at $-\infty$, encircles the point $z$ once counter-clockwise, and returns to the point at $-\infty, C^{+}$is a contour along the cut joining the points $z$ and $\infty+i \Im(z)$, which starts from the point at $\infty$, encircles the point $z$ once counterclockwise, and returns to the point at $\infty$,

$$
\begin{gathered}
f_{v}(z)=c f_{v}(z):=\frac{\Gamma(v+1)}{2 \pi i} \int_{C} \frac{f(\zeta) d \zeta}{(\zeta-z)^{v+1}} \\
\left.v \in \mathbb{R} \backslash \mathbb{Z}^{-} ; \mathbb{Z}^{-}:=\{-1,-2,-3, \ldots\}\right)
\end{gathered}
$$

and

$$
f_{-n}(z):=\lim _{v \rightarrow-n}\left\{f_{v}(z)\right\} \quad(n \in \mathbb{N}),
$$

where $\zeta \neq z$,

$$
-\pi \leqq \arg (\zeta-z) \leqq \pi \quad \text { for } C^{-},
$$

and

$$
0 \leqq \arg (\zeta-z) \leqq 2 \pi \text { for } C^{+},
$$

then $f_{v}(z)(v>0)$ is said to be the fractional derivative of $f(z)$ of order $v$ and $f_{v}(z)(v<0)$ is said to be the fractional integral of $f(z)$ of order $-v$, provided that

$$
\left|f_{v}(\mathrm{z})\right|<\infty \quad(v \in \mathbb{R}) .
$$


Throughout the remainder of this section, we shall simply write $f_{v}$ for $f_{v}(z)$ whenever the argument of the differintegrated function $f$ is clearly understood by the surrounding context. Moreover, in case $f$ is a many-valued function, we shall tacitly consider the principal value of $f$ in this investigation.

Each of the following general results is capable of yielding particular solutions of many simpler families of linear ordinary fractional differintegral equations (cf. Tu et al. [59]) including (for example) the classical differential equations listed above [cf. Equations (4.1) to (4.7)].

Theorem 1. Let $P(z ; p)$ and $Q(z ; q)$ be polynomials in $z$ of degrees $p$ and $q$, respectively, defined by

$$
\begin{aligned}
P(z ; p) & :=\sum_{k=0}^{p} a_{k} z^{p-k} \\
& =a_{0} \prod_{j=1}^{p}\left(z-z_{j}\right) \quad\left(a_{0} \neq 0 ; p \in \mathbb{N}\right)
\end{aligned}
$$

and

$$
Q(z ; q):=\sum_{k=0}^{q} b_{k} z^{q-k} \quad\left(b_{0} \neq 0 ; q \in \mathbb{N}\right)
$$

Suppose also that $f_{v}(\neq 0)$ exists for a given function $f$. equation:

Then the nonhomogeneous linear ordinary fractional differintegral

$$
\begin{aligned}
& P(z ; p) \phi_{\mu}(z)+\left[\sum_{k-1}^{p}\left(\begin{array}{l}
v \\
k
\end{array}\right) P_{k}(z ; p)+\sum_{k=1}^{q}\left(\begin{array}{c}
v \\
k-1
\end{array}\right) Q_{k-1}(z ; q)\right] \phi_{\mu-k}(z) \\
& +\left(\begin{array}{l}
v \\
q
\end{array}\right) q ! b_{0} \phi_{\mu-q-1}(z)=f(z) \\
& (\mu, v \in \mathbb{R} ; \quad p, q \in \mathbb{N}) .
\end{aligned}
$$

has a particular solution of the form:

$$
\begin{gathered}
\phi(z)=\left(\left(\frac{f_{-v}(z)}{P(z ; p)} e^{H(z ; p, q)}\right)_{-1} e^{-H(z ; p, q)}\right)_{v-\mu+1} \\
\left(z \in \mathbb{C} \backslash\left\{z_{1}, \ldots, z_{p}\right\}\right),
\end{gathered}
$$


where, for convenience,

$$
H(z ; p, q):=\int^{z} \frac{Q(\zeta ; q)}{P(\zeta ; p)} d \zeta \quad\left(z \in \mathbb{C} \backslash\left\{z_{1}, \ldots, z_{p}\right\}\right)
$$

provided that the second member of (4.17) exists.

Theorem 2. Under the various relevant hypotheses of Theorem 1, the homogeneous linear ordinary fractional differintegral equation:

$$
\begin{gathered}
P(z ; p) \phi_{\mu}(z)+\left[\sum_{k=1}^{p}\left(\begin{array}{l}
v \\
k
\end{array}\right) P_{k}(z ; p)+\sum_{k=1}^{q}\left(\begin{array}{c}
v \\
k-1
\end{array}\right) Q_{k-1}(z ; q)\right] \phi_{\mu-k}(z) \\
+\left(\begin{array}{l}
v \\
q
\end{array}\right) q ! b_{0} \phi_{\mu-q-1}(z)=0 \\
(\mu, v \in \mathbb{R} ; p, q \in \mathbb{N})
\end{gathered}
$$

has solutions of the form:

$$
\phi(z)=K\left(e^{-H(z ; p, q)}\right)_{v-\mu+1},
$$

where $K$ is an arbitrary constant and $H(z ; p, q)$ is given by (4.18), it being provided that the second member of (4.20) exists.

Next, for a function $u=u(z, t)$ of two independent variables $z$ and $t$, we find it to be convenient to use the notation:

$$
\frac{\partial^{m+v} u}{\partial z^{\mu} \partial t^{v}}
$$

to abbreviate the partial fractional differintegral of $u(z, t)$ of order $\mu$ with respect to $z$ and of order $v$ with respect to $t(\mu, v \in \mathbb{R})$. And we now state the following general result (cf. Tu et al. [59]): 
Theorem 3. Let the polynomials $P(z ; p)$ and $Q(z ; q)$ be defined by (4.14), (4.15), respectively. Suppose also that the function $H(z ; p, q)$ is given by (4.18).

Then the partial fractional differintegral equation:

$$
\begin{gathered}
P(z ; p) \frac{\partial^{\mu} u}{\partial z^{\mu}}+\left[\begin{array}{c}
p-1 \\
k=1
\end{array}\left(\begin{array}{l}
v \\
k
\end{array}\right) P_{k}(z ; p)+\sum_{k=1}^{q}\left(\begin{array}{c}
v \\
k-1
\end{array}\right) Q_{k-1}(z ; q-1)\right] \frac{\partial^{\mu-k} u}{\partial z^{\mu-k}} \\
+\gamma \frac{\partial^{\mu-p} u}{\partial z^{\mu-p}}=\alpha \frac{\partial^{\mu-p+2} u}{\partial z^{\mu-p} \partial t^{2}}+\beta \frac{\partial^{\mu-p+1} u}{\partial z^{\mu-p} \partial t} \\
(\mu, v \in \mathbb{R} ; p, q \in \mathbb{N})
\end{gathered}
$$

has solutions of the form:

$$
u(z, t)=\left\{\begin{array}{lc}
K_{1}\left(e^{-H(z ; p, q-1)}\right)_{v-\mu+1} e^{\xi t} & (\alpha \neq 0) \\
K_{2}\left(e^{-H(z ; p, q-1)}\right)_{v-\mu+1} e^{\eta t} & \alpha=0 ; \beta \neq 0)
\end{array}\right.
$$

where $K_{1}$ and $K_{2}$ are arbitrary constants, $\alpha, \beta$, and $\gamma$ are given constants, and (for convenience)

$$
\xi:=\frac{-\beta \pm \sqrt{\beta^{2}+4(\gamma-\delta) \alpha}}{2 \alpha} \quad(\alpha \neq 0) \text { and } \eta:=\frac{\gamma-\delta}{\beta} \quad(\alpha=0 ; \beta \neq 0),
$$

with

$$
\delta:=\left(\begin{array}{l}
v \\
p
\end{array}\right) p ! \alpha_{0},
$$

provided that the second member of (4.22) exists in each case.

We conclude this section by remarking further that either or both of the polynomials $P(z ; p)$ and $Q(z ; q)$, involved in Theorems 1 to 3 , can be of degree 0 as well. Thus, in the definitions (4.14) and (4.15) (as also in Theorems 1 to 3 ), $\mathbb{N}$ may easily be replaced (if and where needed) by $\mathbb{N}_{0}$. Furthermore, it is fairly straightforward to see how each of these general theorems can be suitably specialized to yield numerous simpler results scattered throughout the evergrowing literature on fractional calculus. 


\section{APPLICATIONS INVOLVING A CLASS OF NON-FUCHSIAN DIFFERENTIAL EQUATIONS}

In this section, we aim at applying Theorem 1 in order to find (explicit) particular solutions of the following general class of non-Fuchsian differential equations with six parameters:

$$
\begin{gathered}
\left(1+\frac{l}{\mathrm{z}}\right) \frac{d^{2} \varphi}{d z^{2}}+\left[\alpha+\frac{\beta}{z}\left(1+\frac{l}{z}\right)\right] \frac{d \varphi}{d z}+\left[\gamma+\frac{\delta}{z}+\frac{\varepsilon}{z^{2}}\left(1+\frac{l}{z}\right)\right] \varphi(z) \\
=f(z) \quad(z \in \mathbb{C} \backslash\{0,-1\}) .
\end{gathered}
$$

where $f$ is a given function and the parameters $\alpha, \beta, \gamma, \delta, \varepsilon$, and $l$ are unrestricted, in general. Indeed, if we make use of the transformation:

$$
\varphi(z)=z^{\rho} e^{\lambda z} \phi(z),
$$

constrain the various parameters involved in (5.1) and (5.2) so that

$$
\rho=-\frac{1}{2} \beta=\frac{-1 \pm \sqrt{1+4 \varepsilon}}{2} \text { end } \lambda=\frac{-\alpha \pm \sqrt{\alpha^{2}+4 \gamma}}{2}
$$

then Theorem 1 would eventually imply that the nonhomogeneous linear ordinary differential equation (5.1) has a particular solution in the form:

$$
\begin{gathered}
\varphi(z)=z^{\rho} e^{\lambda z} \phi(z)=z^{\rho} e^{\lambda z}\left(\left(\left(z^{1-\rho} e^{-\lambda z} f(z)\right)_{-v} \cdot(z+l)^{-v-\alpha l-1} \cdot e^{(2 \lambda+\alpha) z}\right)_{-1}\right. \\
\left.(z+l)^{v+\alpha l} \cdot e^{-(2 \lambda+\alpha) z}\right)_{\nu-1} \quad(z \in \mathbb{C} \backslash\{0,-l\} ; v \in \mathbb{R}),
\end{gathered}
$$

and (by Theorem 2) the corresponding homogeneous linear ordinary differential equation:

$$
\begin{gathered}
\left(1+\frac{l}{z}\right) \frac{d^{2} \varphi}{d z^{2}}+\left[\alpha+\frac{\beta}{z}\left(1+\frac{l}{z}\right)\right] \frac{d \varphi}{d z}+\left[\gamma+\frac{\delta}{Z}+\frac{\varepsilon}{z^{2}}\left(1+\frac{l}{z}\right)\right] \varphi(z)=0 \\
(z \in \mathbb{C} \backslash\{0,-1\}),
\end{gathered}
$$

has solutions given by, 


$$
\begin{gathered}
\varphi(z)=z^{\rho} e^{\lambda z} \varphi(z)=K z^{\rho} e^{\lambda z}\left((z+l)^{v+\alpha l} \cdot e^{-(2 \lambda+\alpha) z}\right)_{v-1} \\
(z \in \mathbb{C} \backslash\{0,-1\} ; v \in \mathbb{R})
\end{gathered}
$$

where $K=\$$ is an arbitrary constant, the parameters $\rho$ and $\lambda$ are given (as before) by (2.3), and

$$
v=\frac{\lambda^{2} l+\rho \alpha+\delta}{2 \lambda+\alpha} .
$$

For various special choices for the free parameters occurring in (5.1) and (5.5), one can apply the results of this section to many known non-Fuchsian differential equations. These include (for example) a special limit (confluent) case of the Gauss hypergeometric equation (4.1), referred to as the Whittaker equation (cf., e.g., [66, p. 337, Equation 16.1 (B)]; see also [5, Vol. I, p. 248, Equation 6.1 (4)]), the so-called Fukuhara equation (cf. [7]; see also [33]), the Tricomi equation (cf. [45, p. 7, Equation 1.2 (1)]; see also [5, Vol. I, p. 251, Equation 6.2 (13)]), the familiar Bessel equation (cf. [65]), and so on. For a systematic investigation of these and many other closely-related differential equations (including, for example, many of the familiar differential equations list at the beginning of Section 4 here), we refer the interested reader to the recent works of Nishimoto et al. ([32] to [38]), Salinas de Romero et al. ([45] and [46]), Galué [8], Lin et al. ([20] to [25]), Tu et al. ([59] to [62]), and Wang et al. ([63] and [64]).

\section{THE CLASSICAL GAUSS AND JACOBI DIFFERENTIAL EQUATIONS REVISITED}

The main purpose of this section (and Section 7 below) is to follow rather closely and analogously the investigations in (for example) [16], [23], [53], [63] and [64] of solutions of some general families of second-order linear ordinary differential equations, which are associated with the familiar Bessel differential equation of general order $v(c f$. [5], Vol. II, Chapter 7]; see also [65] and [66, Chapter 17]):

$$
z^{2} \frac{d^{2} w}{d z^{2}}+z \frac{d w}{d z}+\left(z^{2}-v^{2}\right) w=0
$$

which is named after Friedrich Wilheim Bessel (1784-1846). More precisely, just as in the earlier works [21] and [53] (see also [17] and [18]), which dealt 
systematically with Legendre's differential equation (cf. [5. Vol. I, p. 121, Equation 3.2 (1)]; see also [66, Chapter 15]):

$$
\left(1-z^{2}\right) \frac{d^{2} w}{d z^{2}}+-2 z \frac{d w}{d z}+\left(v(v+1)-\frac{\mu^{2}}{1-z^{2}}\right) w=0,
$$

we aim here in this section at demonstrating how the underlying simple fractional-calculus approach to the solutions of the classical differential equations (6.1) and (6.2) would lead us analogously to several interesting consequences including (for example) an alternative investigation of solutions of the following two-parameter family of second-order ordinary differential equations (see also [63]):

$$
z(1-z) \frac{d^{2} w}{d z^{2}}+[(\rho-2 \lambda) z+\lambda+\sigma] \frac{d w}{d z}+\lambda(\rho-\lambda+1) w=0,
$$

We begin by setting

$$
\begin{gathered}
\mu=2, v \mapsto \lambda, p-1=q=1, a_{0}=-1, a_{1}=1, a_{2}=0, b_{0}=\rho \text {, and } b_{1}=\sigma \\
(\rho \neq 0 ; \lambda \in \mathbb{R})
\end{gathered}
$$

in Theorem 1. We can thus deduce the following application of Theorem 1 relevant to the linear ordinary differential equation (6.3).

Theorem 4. If the given function $f$ satisfies the constraint (4.13) and $f_{-\lambda} \neq 0$, then the following nonhomogeneous linear ordinary differential equation:

$$
\begin{gathered}
z(1-z) \frac{d^{2} \phi}{d z^{2}}+[(\rho-2 \lambda) z+\lambda+\sigma] \frac{d \phi}{d z}+\lambda(\rho-\lambda+1) \phi=f(z) \\
(z \in \mathbb{C} \backslash\{0,1\} ; \rho \neq 0 ; \lambda \in \mathbb{R})
\end{gathered}
$$

has a particular solution of the form:

$$
\begin{gathered}
\phi(z)=\left(\left(f_{-\lambda}(z) \cdot z^{\sigma-1} \cdot(1-z)^{-\rho-\sigma-1}\right)_{-1} \cdot z^{-\sigma} \cdot(1-z)^{\rho+\sigma}\right)_{\lambda-1} \\
(z \in \mathbb{C} \backslash\{0,1\} ; \rho \neq 0 ; \lambda \in \mathbb{R})
\end{gathered}
$$

provided that the second member of (6.6) exists. 
Furthermore, the following homogeneous linear ordinary differential equation:

$$
\begin{gathered}
z(1-z) \frac{d^{2} \phi}{d z^{2}}+[(\rho-2 \lambda) z+\lambda+\sigma] \frac{d \phi}{d z}+\lambda(\rho-\lambda+1) \phi=0 \\
(z \in \mathbb{C} \backslash\{0,1\} ; \rho \neq 0 ; \lambda \in \mathbb{R})
\end{gathered}
$$

has solutions of the form:

$$
\phi(z)=K\left(z^{-\sigma} \cdot(1-z)^{\rho+\sigma}\right)_{\lambda-1} \quad(z \in \mathbb{C} \backslash\{0,1\} ; \rho \neq 0 ; \lambda \in \mathbb{R}),
$$

were $K$ is an arbitrary constant, it being provided that the second member of (6.8) exists.

Remark 1. If we consider the case when $|z|<1$, by making use of the familiar binomial expansion, we find from the assertion (2.5) of Theorem 4 that

$$
\phi(z)=K \sum_{n=0}^{\infty}(-1)^{n}\left(\begin{array}{c}
\rho+\sigma \\
n
\end{array}\right)\left(z^{n-\sigma}\right)_{\lambda-1} \quad(|z|<1) .
$$

Thus, in view of the following well-exploited fractional differintegral formula:

$$
\begin{gathered}
\left(z^{\lambda}\right)_{v}=e^{-i \pi v} \frac{\Gamma(v-\lambda)}{\Gamma(-\lambda)} z^{\lambda-v} \\
\left(v \in \mathbb{R} ; z \in \mathbb{C} ;\left|\frac{\Gamma(v-\lambda)}{\Gamma(-\lambda)}\right|<\infty\right)
\end{gathered}
$$

we readily obtain

$$
\begin{aligned}
\phi(z)=K e^{-i \pi(\lambda-1)} \frac{\Gamma(\lambda+\sigma-1)}{\Gamma(\sigma)} z^{1-\lambda-\sigma} . \\
{ }_{2} F_{1}(-\rho-\sigma, 1-\sigma ; 2-\lambda-\sigma ; z) \quad(|z|<1)
\end{aligned}
$$

in terms of the Gauss hypergeometric function ${ }_{2} F_{1}$ (see [5, Vol. I, Chapter 2]).

Remark 2. If we consider the case when $|z|>1$, by appropriately applying the familiar binomial expansion once again, we find from the assertion (6.8) of Theorem 4 that 


$$
\varphi(z)=K e^{-i \pi(\rho+\sigma)} \sum_{n=0}^{\infty}(-1)^{n}\left(\begin{array}{c}
\rho+\sigma \\
n
\end{array}\right)\left(z^{\rho-n}\right)_{\lambda-1} \quad(|z|>1)
$$

Thus, in view of the fractional differintegral formula (6.10), we find the following explicit solution of the differential equation (6.7) when $|z|>1$ :

$$
\begin{aligned}
\varphi(z)= & K e^{-i \pi(\lambda+\rho+\sigma-1)} \frac{\Gamma(\lambda-\rho-1)}{\Gamma(-\rho)} z^{\rho-\lambda+1} \\
& \cdot{ }_{2} F_{1}\left(-\rho-\sigma, \lambda-\rho-1 ; \rho ; \frac{1}{z}\right) \quad(|z|<1),
\end{aligned}
$$

in terms of the Gauss hypergeometric function ${ }_{2} F_{1}$ (see [5, Vol. I, Chapter 2]).

\section{A FAMILY OF UNIFIED ALTERNATIVE SOLUTIONS RESULTING FROM THEOREM 4}

We now propose to develop alternative solutions of several classical differential equations of mathematical physics in a unified manner by suitably applying the assertions of Theorem 4, Remark 1, and Remark 2.

I. Gauss's Differential Equation [see also Equation (4.1)]:

$$
z(1-z) \frac{d^{2} \varphi}{d z^{2}}+[\gamma-(\alpha+\beta+1) z] \frac{d \varphi}{d z}-\alpha \beta \varphi=0,
$$

which possesses the following well-known power-series solution relative to the regular singular point $z=0$ (see, for example, [12, p. 162]):

$$
\varphi^{(1)}(z)={ }_{2} F_{1}(\alpha, \beta ; \gamma ; z) \quad(|z|<1)
$$

Furthermore, upon setting

$$
\lambda=\alpha, \rho=\alpha-\beta-1 \text { and } \sigma=\gamma-\alpha
$$

in (6.11), we obtain the following explicit solution of (7.1):

$$
\varphi^{(2)}(z)=z^{1-\gamma}{ }_{2} F_{1}(\alpha-\gamma+1, \beta-\gamma+1 ; 2-\gamma ; z) \quad(|z|<1)
$$


Thus, by combining the linearly independent solutions $\varphi^{(1)}(z)$ and $\varphi^{(2)}(z)$, we find the following well-known general solution of the Gauss differential equation (7.1) by means of fractional calculus:

$$
\begin{aligned}
& \varphi(z)=K_{1} \varphi^{(1)}(z)+K_{2} \varphi^{(2)}(z) \\
& =K_{12} F_{1}(\alpha, \beta ; \gamma ; z)+K_{2} z^{1-\gamma}{ }_{2} F_{1}(\alpha-\gamma+1, \beta-\gamma+1 ; 2-\gamma ; z) \quad(|z|<1),(7.4)
\end{aligned}
$$

where $K_{1}$ and $K_{2}$ are arbitrary constants, it being understood that each member of (7.4) exists.

Alternatively, if we set

$$
\lambda=\beta, \quad \rho=\beta-\alpha-1 \quad \text { and } \quad \alpha=\gamma-\beta
$$

in (6.13), then we obtain the following explicit solution of (7.1) [12, p. 162]:

$$
\varphi^{(3)}(z)=z_{2}^{-\alpha} F_{1}\left(\alpha, \alpha-\gamma+1 ; \alpha-\beta+1 ; \frac{1}{z}\right) \quad(|z|<1),
$$

If, on the other hand, we choose to set

$$
\lambda=\alpha, \quad \rho=\alpha-\beta-1 \quad \text { and } \quad \sigma=\gamma-\alpha
$$

in (6.12), then we obtain the following further explicit solution of (7.1) [12, p. 162]:

$$
\varphi^{(4)}(z)=z^{-\beta} F_{1}\left(\beta-\gamma+1, \beta ; \beta-\alpha+1 ; \frac{1}{z}\right) \quad(|z|<1),
$$

which does indeed follow also from (7.5) upon interchanging the röles of the parameters $\alpha$ and $\beta$. Thus, if we combine the solutions $\varphi^{(3)}(z)$ and $\varphi^{(4)}(z)$ appropriate to the point at infinity, we find the following general solution of the Gauss differential equation (7.1) by means of fractional calculus:

$$
\begin{aligned}
\varphi(z)= & K_{1}^{*} \varphi^{(3)}(z)+K_{2}^{*} \varphi^{(4)}(z) \\
=K_{1}^{*} z^{-\alpha}{ }_{2} F_{1}\left(\alpha, \alpha-\gamma+1 ; \alpha-\beta+1 ; \frac{1}{z}\right) & \\
& \quad+K_{2}^{*} z^{-\beta}{ }_{2} F_{1}\left(\beta-\gamma+1, \beta ; \beta-\alpha+1 ; \frac{1}{z}\right) \quad(|z|<1),
\end{aligned}
$$


where $K_{1}^{*}$ and $K_{2}^{*}$ are arbitrary constants, it being understood that each member of (7.7) exists.

Lastly, since any solution of the Gauss differential equation (7.1) is linearly expressible in terms of two linearly independent solutions (see, e.g., $[12$, p. 168]), it is not difficult to deduce from the above observations that (see, for example, [5, Vol. I, p. 108, Equation 2.10 (2)])

$$
\begin{aligned}
&{ }_{2} F_{1}(\alpha, \beta ; \gamma ; z)= A(-z)^{-\alpha}{ }_{2} F_{1}\left(\alpha, \alpha-\gamma+1 ; \alpha-\beta+1 ; \frac{1}{z}\right) \\
&+B(-z)^{-\beta}{ }_{2} F_{1}\left(\beta-\gamma+1, \beta ; \beta-\alpha+1 ; \frac{1}{z}\right) \\
&(|z|>1 ; \quad|\arg (-z)| \leqq \pi-\varepsilon ; \quad 0<\varepsilon<\pi) .
\end{aligned}
$$

where, for convenience, the coefficients $A$ and $B$ are given by

$$
A:=\frac{\Gamma(\gamma) \Gamma(\beta-\alpha)}{\Gamma(\beta) \Gamma(\gamma-\alpha)} \quad \text { and } \quad B:=\frac{\Gamma(\gamma) \Gamma(\alpha-\beta)}{\Gamma(\alpha) \Gamma(\gamma-\beta)}
$$

The analytic continuation formula (7.8) is usually derived by the calculus of residues and the Mellin-Barnes contour integral representation for the Gauss hypergeometric function occurring on its left-hand side (see, for details, [5, Vol. I, p. 62, Section 2.1.4]). Moreover, it is easily seen from this analytic continuation formula (7.8) that asymptotically, for large $|z|$, we have

$$
\begin{gathered}
{ }_{2} F_{1}(\alpha, \beta ; \gamma ; z) \sim A(-z)^{-\alpha}+B(-z)^{-\beta} \\
(|z| \rightarrow \infty ;|\arg (-z)| \leqq \pi-\varepsilon ; \quad 0<\varepsilon<\pi),
\end{gathered}
$$

where the coefficients $A$ and $B$ are given (as before) by (7.9).

\section{Jacobi's Differential Equation:}

$$
\left(1-z^{2}\right) \frac{d^{2} \Theta}{d z^{2}}+[\beta-\alpha-(\alpha+\beta+2) z] \frac{d \Theta}{d z}+v(v+\alpha+\beta+1) \Theta=0,
$$


which in its special case when $v=n \in \mathbb{N}_{0}$, would reduce to the relatively more familiar differential equation satisfied by the classical Jacobi polynomials $P_{n}^{(\alpha, \beta)}(\mathrm{z})$ given explicitly by

$$
\begin{gathered}
P_{n}^{(\alpha, \beta)}(z)=\sum_{k=0}^{n}\left(\begin{array}{c}
n+\alpha \\
k
\end{array}\right)\left(\begin{array}{c}
n+\beta \\
n-k
\end{array}\right)\left(\frac{z-1}{2}\right)^{n-k}\left(\frac{z+1}{2}\right)^{k} \\
-\left(\begin{array}{c}
n+\alpha \\
n
\end{array}\right){ }_{2} F_{1}\left(-n, n+\alpha+\beta+1 ; \alpha+1 ; \frac{1-z}{2}\right) .
\end{gathered}
$$

Indeed, upon setting

$$
z \mapsto 1-2 z, \quad \frac{d}{d z} \mapsto-\frac{1}{2} \frac{d}{d z}, \quad \frac{d^{2}}{d z^{2}} \mapsto \frac{1}{4} \frac{d^{2}}{d z^{2}} \quad \text { and } \quad \Theta \mapsto \Phi .
$$

Jacobi's differential equation (7.11) assumes the following form:

$$
z(1-z) \frac{d^{2} \Phi}{d z^{2}}+[\alpha+1-(\alpha+\beta+2) z] \frac{d \Phi}{d z}+v(v+\alpha+\beta+1) \Phi=0
$$

Clearly, we have

$$
\Theta(1-2 z)=\Phi(z) \quad \text { and } \quad \Theta(z)=\Phi\left(\frac{1-z}{2}\right) .
$$

By setting

$$
\lambda=v+\alpha+\beta+1, \quad \rho=2 v+\alpha+\beta \quad \text { and } \quad \sigma=-v-\beta
$$

in (6.11) and (6.13), or (alternatively) by directly applying the hypergeometric solutions given by (7.2), (7.3), (7.5) and (7.6), we obtain the following explicit solutions of (7.13):

$$
\begin{array}{cc}
\Phi^{(1)}(z)={ }_{2} F_{1}(-v, v+\alpha+\beta+1 ; \alpha+1 ; z) & (|z|<1), \\
\Phi^{(2)}(z)=z^{-\alpha}{ }_{2} F_{1}(-v-\alpha, v+\beta+1 ; 1-\alpha ; z) & (|z|<1), \\
\Phi^{(3)}(z)=z_{2}^{v} F_{1}\left(-v,-v-\alpha ;-2 v-\alpha-\beta ; \frac{1}{z}\right) & (|z|>1)
\end{array}
$$


and

$$
\Phi^{(4)}(z)=z^{-v-\alpha-\beta-1}{ }_{2} F_{1}\left(v+\beta+1, v+\alpha+\beta+1 ; 2 v+\alpha+\beta+2 ; \frac{1}{z}\right) \quad(|z|>1) .
$$

Thus, if we make use of the relationships given by (7.14) in our observations (7.15) to (7.18), we are led fairly easily to the following explicit solutions of the general Jacobi differential equation (7.11):

$$
\begin{gathered}
\Theta^{(1)}(z)={ }_{2} F_{1}\left(-v, v+\alpha+\beta+1 ; \alpha+1 ; \frac{1-z}{2}\right) \quad(|1-z|<2), \\
\Theta^{(2)}(z)=(1-z)^{-\alpha}{ }_{2} F_{1}\left(-v-\alpha, v+\beta+1 ; 1-\alpha ; \frac{1-z}{2}\right) \quad(|1-z|<2),(7,2) \\
\Theta^{(3)}(z)=(1-z)^{v}{ }_{2} F_{1}\left(-v, v-\alpha ;-2 v-\alpha-\beta ; \frac{2}{1-z}\right) \quad(|1-z|<2)
\end{gathered}
$$

and

$$
\Theta^{(4)}(z)=(1-z)^{-v-\alpha-\beta-1}{ }_{2} F_{1}\left(v+\beta+1, v+\alpha+\beta+1 ; 2 v+\alpha+\beta+2 ; \frac{2}{1-z}\right)
$$

Remark 3. The solution $\Theta^{(1)}(z)$ given by (7.19) can indeed be rewritten in terms of the classical Jacobi function $P_{v}^{(\alpha, \beta)}(z)(v \in \mathbb{C})$ defined by

$$
\begin{aligned}
P_{v}^{(\alpha, \beta)}(z) & :=\sum_{k=0}^{\infty}\left(\begin{array}{c}
v+\alpha \\
k
\end{array}\right)\left(\begin{array}{c}
v+\beta \\
v-k
\end{array}\right)\left(\frac{z-1}{2}\right)^{v-k}\left(\frac{z+1}{2}\right)^{k} \\
= & \left(\begin{array}{c}
v+a \\
v
\end{array}\right){ }_{2} F_{1}\left(-v, v+\alpha+\beta+1 ; \alpha+1 ; \frac{1-z}{2}\right) \quad(v \in \mathbb{C}) .
\end{aligned}
$$

Remark 4. In view of the familiar Euler transformation (see, for example [5, Vol. I, p. 64, Equation 2.1.4 (23)]): 


$$
\begin{gathered}
{ }_{2} F_{1}(\alpha, \beta ; \gamma ; z)=(1-z)^{-\gamma-\alpha-\beta}{ }_{2} F_{1}(\gamma-\alpha, \gamma-\beta ; \gamma ; z) \\
(|\arg (1-z)| \leqq \pi-\varepsilon ; \quad 0<\varepsilon<\pi),
\end{gathered}
$$

we can rewrite the solution $\Theta^{(4)}(z)$ given by (7.22) in the following equivalent form:

$$
\begin{gathered}
\Theta^{(4)}(z)=\frac{2^{v+\alpha+\beta+1} e^{i \pi \beta}}{(1-z)^{v+\alpha+1}(1+z)^{\beta}}{ }_{2} F_{1}\left(v+1, v+\alpha+1 ; 2 v+\alpha+\beta+2 ; \frac{2}{1-z}\right) \\
(|1-z|>2 ; \quad v \in \mathbb{C}),
\end{gathered}
$$

which obviously is expressible in terms of the Jacobi function of the second kind defined by (cf., e.g., [5, Vol. II, p. 170, Equation 10.8 (18)])

$$
\begin{gathered}
Q_{v}^{(\alpha, \beta)}(z):=\frac{2^{v+\alpha+\beta} \Gamma(v+\alpha+1) \Gamma(v+\beta+1)}{(z-1)^{v+\alpha+1}(z+1)^{\beta} \Gamma(2 v+\alpha+\beta+2)} \\
{ }_{2} F_{1}\left(v+1, v+\alpha+1 ; 2 v+\alpha+\beta+2 ; \frac{2}{1-z}\right) \\
(|1-z|>2 ; \quad v \in \mathbb{C})
\end{gathered}
$$

In conclusion, we observe that such general results as Theorems 1 to 3 and their various companions (proven by Tu et al. [59]) can be applied similarly in order to derive explicit solutions of many other interesting families of ordinary and partial differential equations.

\section{FURTHER MISCELLANEOUS APPLICATIONS OF FRACTIONAL CALCULUS}

For the purpose of those readers who are interested in pursuing investigations on the subject of fractional calculus, we give here references to some of the other applications of fractional calculus operators in the mathematical sciences, which are not mentioned in the preceding sections.

(i) Theory of Generating Functions of Orthogonal Polynomials and Special Functions (cf. [54]); 
(ii) Geometric Function Theory (especially the Theory of Analytic, Univalent, and Multivalent Functions) (cf. [55] and [56]);

(iii) Integral Equations (cf. [10], [49] and [50);

(iv) Integral Transforms ( $c f .[15]$ and [26]);

(v) Generalized Functions (cf. [26]);

(vi) Theory of Potentials ( $c f$. [44]).

A remarkably significant number of publications are emerging regularly in many of these additional areas of applications of fractional calculus as well.

Acknowledgements: The present investigation was supported, in part, by the Natural Sciences and Engineering Research Council of Canada under Grant OGP0007353. Indeed it is a great pleasure for me to express my sincere thanks to the Macedonian Academy of Sciences and Arts (especially Academician Blagoj Sazdov Popov; its Past President, Academician Cvetan Grozdanov; its current President, Academician Georgi Stardelov; and the Head of its Division of Mathematical and Technical Sciences, Academician Bojan Šoptrajanov) for the kind invitation and excellent hospitality on the occasion of my formal installation as an Honorary Academician and Foreign Member of the Academy on 07 November 2007.

\section{REFERENCES}

[1] C. M. Carracedo and M. S. Alix, The Theory of Fractional Powers of Operators, North-Holland Mathematical Studies, Vol. 187, Elsevier (North-Holland) Science Publishers, Amsterdam, London and New York, 2001.

[2] M. M. El-Borai, Some probability densities and fundamental solutions of fractional evolution equations, Chaos Solitons Fractals, 14 (2002), 433-440.

[3] M. M. El-Borai, Semigroups and some nonlinear fractional differential equations, Appl. Math. Comput. 149 (2004), 823-831.

[4] M. M. El-Borai, The fundamental solutions for fractional evolution equations of parabolic type, J. Appl. Math. Stochast. Anal. 2004 (2004), 197-211.

[5] A. Erdélyi, W. Magnus, F. Oberhettinger and F. G. Tricomi, Higher Transcendental Functions, Vols. I and II, McGraw-Hill Book Company, New York, Toronto and London, 1953.

[6] A. Erdélyi, W. Magnus, F. Oberhettinger and F. G. Tricomi, Tables of Integral Transforms, Vol. II, McGraw-Hill Book Company, New York, Toronto and London, 1954.

[7] M. Fukuhara, Ordinary Differential Equations, Vol. II, Iwanami Shoten, Tokyo, 1941 (Japanese). 
[8] L. Galué, $N$-fractional calculus operator $\mathcal{N}^{v}$ method applied to some second order nonhomogeneous equations, J. Fract. Calc. 16 (1999), 85-97.

[9] R. Gorenflo, F. Mainardi and H. M. Srivastava, Special functions in fractional relaxation-oscillation and fractional diffusion-wave phenomena, Proceedings of the Eighth International Colloquium on Differential Equations, (Plovdiv, Bulgaria; August 18-23, 1997) (D. Bainov, Editor), VSP Publishers, Utrecht and Tokyo, 1998, pp. 195-202.

[10] R. Gorenflo and S. Vessela, Abel Integral Equations: Analysis and Applications, Lecture Notes in Mathematics, Vol. 1461, Springer-Verlag, Berlin, Heidelberg, New York and London, 1991.

[11] R. Hilfer (Editor), Applications of Fractional Calculus in Physics, World Scientific Publishing Company, Singapore, New Jersey, London and Hong Kong, 2000.

[12] E. L. Ince, Ordinary Differential Equations, Longmans, Green and Company, London, 1927; Reprinted by Dover Publications, New York, 1956.

[13] R. N. Kalia (Editor), Recent Advances in Fractional Calculus, Global Publishing Company, Sauk Rapids (Minnesota), 1993.

[14] A. A. Kilbas, H. M. Srivastava and J. J. Trujillo, Theory and Applications of Fractional Differential Equations, North-Holland Mathematical Studies, Vol. 204, Elsevier (North-Holland) Science Publishers, Amsterdam, London and New York, 2006.

[15] V. Kiryakova, Generalized Fractional Calculus and Applications, Pitman Research Notes in Mathematics, Vol. 301, Longman Scientific and Technical, Harlow (Essex), 1993

[16] S.-D. Lin, W.-C. Ling, K. Nishimoto and H. M. Srivastava, A simple fractionalcalculus approach to the solutions of the Bessel differential equation of general order and some of its applications, Comput. Math. Appl. 49 (2005), 1487-1498.

[17] S.-D. Lin and K. Nishimoto, $N$-Method to a generalized associated Legendre equation, J. Fract. Calc. 14 (1998), 95-111.

[18] S.-D. Lin and K. Nishimoto, New finding of particular solutions for a generalized associated Legendre equation, J. Fract. Calc. 18 (2000), 9-37.

[19] S.-D. Lin, K. Nishimoto, T. Miyakoda and H. M. Srivastava, Some differintegral formulas for power, composite and rational functions, J. Fract. Calc. 32 (2000), 87-98.

[20] S.-D. Lin, H. M. Srivastava, S.-T. Tu and P.-Y. Wang, Some families of linear ordinary and partial differential equations solvable by means of fractional calculus, Internat. J. Differential Equations Appl. 4 (2002), 405-421.

[21] S.-D. Lin, Y.-S. Tsai and P.-Y. Wang, Explicit solutions of a certain class of associated Legendre equations by means of fractional calculus, Appl. Math. Comput. 187 (2007), 280-289.

[22] S.-D. Lin, S.-T. Tu, I-C. Chen and H. M. Srivastava, Explicit solutions of a certain family of fractional differintegral equations, Hyperion Sci. J. Ser. A Math. Phys. Electric. Engrg. 2 (2001), 85-90. 
[23] S.-D. Lin, S.-T. Tu and H. M. Srivastava, Explicit solutions of certain ordinary differential equations by means of fractional calculus, J. Fract. Calc. 20 (2001), 35-43.

[24] S.-D. Lin, S.-T. Tu and H. M. Srivastava, Certain classes of ordinary and partial differential equations solvable by means of fractional calculus, Appl. Math. Comput. 131 (2002), 223-233.

[25] S.-D. Lin, S.-T. Tu and H. M. Srivastava, Explicit solutions of some classes of nonFuchsian differential equations by means of fractional calculus, J. Fract. Calc. 21 (2002), 49-60.

[26] A. C. McBride, Fractional Calculus and Integral Transforms of Generalized Functions, Pitman Research Notes in Mathematics, Vol. 31, Pitman Publishing Limited, London, 1979.

[27] A. C. McBride and G. F. Roach (Editors), Fractional Calculus (Glasgow, Scotland; August 5-11, 1984), Pitman Research Notes in Mathematics, Vol. 138, Pitman Publishing Limited, London, 1985.

[28] K. S. Miller and B. Ross, An Introduction to the Fractional Calculus and Fractional Differential Equations, A Wiley-Interscience Publication, John Wiley and Sons, New York, Chichester, Brisbane, Toronto and Singapore, 1993.

[29] K. Nishimoto, Fractional Calculus, Vols. I, II, III, IV, and V, Descartes Press, Koriyama, 1984, 1987, 1989, 1991, and 1996.

[30] K. Nishimoto (Editor), Fractional Calculus and Its Applications (Tokyo; May 29 June 1, 1989), Nihon University (College of Engineering), Koriyama, 1990.

[31] K. Nishimoto, An Essence of Nishimoto's Fractional Calculus Calculus of the 21st Century): Integrations and Differentiations of Arbitrary Order, Descartes Press, Koriyama, 1991.

[32] K. Nishimoto, Operator $\mathcal{N}^{v}$ method to nonhomogeneous Gauss and Bessel equations, J. Fract. Calc. 9 (1996), 1-15.

[33] K. Nishimoto, J. Aular de Durán and L. Galué, $N$-Fractional calculus operator $\mathcal{N}^{v}$ method to nonhomogeneous Fukuhara equations. I, J. Fract. Calc. 9 (1996), 23-31.

[34] K. Nishimoto and S. Salinas de Romero, $N$-Fractional calculus operator $\mathcal{N}^{v}$ method to nonhomogeneous and homogeneous Whittaker equations. I, J. Fract. Calc. 9 (1996), 17-22.

[35] K. Nishimoto, S. Salinas de Romero, J. Matera and A. I. Prieto, N-Method to the homogeneous Whittaker equations, J. Fract. Calc. 15 (1999), 13-23.

[36] K. Nishimoto, S. Salinas de Romero, J. Matera and A. I. Prieto, N-Method to the homogeneous Whittaker equations (Revise and Supplement), J. Fract. Calc. 16 (1999), 123-128.

[37] K. Nishimoto, H. M. Srivastava and S.-T. Tu, Application of fractional calculus in solving certain classes of Fuchsian differential equations, J. College Engrg. Nihon Univ. Ser. B 32 (1991), 119-126. 
[38] K. Nishimoto, H. M. Srivastava and S.-T. Tu, Solutions of some second-order linear differential equations by means of fractional calculus, J. College Engrg. Nihon Univ. Ser. B 33 (1992), 15-25.

[39] K. B. Oldham and J. Spanier, The Fractional Calculus: Theory and Applications of Differentiation and Integration to Arbitrary Order, Academic Press, New York and London, 1974.

[40] H. M. Ozaktas, Z. Zalevsky and M. A. Kutay, The Fractional Fourier Transform with Applications in Optics and Signal Processing, Wiley Series in Pure and Applied Optics, John Wiley and Sons, New York, Chichester, Brisbane, Toronto and Singapore, 2000.

[41] I. Podlubny, Fractional Differential Equations: An Introduction to Fractional Derivatives, Fractional Differential Equations, to Methods of Their Solution and Some of Their Applications, Mathematics in Science and Engineering, Vol. 198, Academic Press, New York, London, Sydney, Tokyo and Toronto, 1999.

[42] A. I. Prieto, S. Salinas de Romero and H. M. Srivastava, Some fractional calculus results involving the generalized Lommel-Wright and related functions, Appl. Math. Lett., 20 (2007), 17-22.

[43] B. Ross (Editor), Fractional Calculus and Its Applications (West Haven, Connecticut; June 15-16, 1974), Lecture Notes in Mathematics, Vol. 457, Springer-Verlag, Berlin, Heidelberg and New York, 1975.

[44] B. Rubin, Fractional Integrals and Potentials, Pitman Monographs and Surveys in Pure and Applied Mathematics, Longman Scientific and Technical, Harlow (Essex), 1996.

[45] S. Salinas de Romero and K. Nishimoto, $N$-Fractional calculus operator $\mathcal{N}^{v}$ method to nonhomogeneous and homogeneous Whittaker equations. II (Some illustrative examples), J. Fract. Calc., 12 (1997), 29-35.

[46] S. Salinas de Romero and H. M. Srivastava, An application of the $N$-fractional calculus operator method to a modified Whittaker equation, Appl. Math. Comput., 115 (2000), 11-21.

[47] S. G. Samko, A. A. Kilbas and O. I. Marichev, Integrals and Derivatives of Fractional Order and Some of Their Applications (in Russian), „Nauka i Tekhnika“, Minsk, 1987.

[48] S. G. Samko, A. A. Kilbas and O. I. Marichev, Fractional Integrals and Derivatives: Theory and Applications, Gordon and Breach Science Publishers, Reading, Tokyo, Paris, Berlin and Langhorne (Pennsylvania), 1993.

[49] H. M. Srivastava and R. G. Buschman, Convolution Integral Equations with Special Function Kernels, Halsted Press, John Wiley and Sons, New York, 1977.

[50] H. M. Srivastava and R. G. Buschman, Theory and Applications of Convolution Integral Equations, Kluwer Series on Mathematics and Its Applications, Vol. 79, Kluwer Academic Publishers, Dordrecht, Boston and London, 1992.

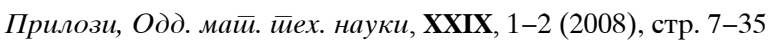


[51] H. M. Srivastava, K. C. Gupta and S. P. Goyal, The H-Functions of One and Two Variables with Applications, South Asian Publishers, New Delhi and Madras, 1982.

[52] H. M. Srivastava and B. R. K. Kashyap, Special Functions in Queuing Theory and Related Stochastic Processes, Academic Press, New York, London, and Toronto, 1982.

[53] H. M. Srivastava, S.-D. Lin, Y.-T. Chao and P.-Y. Wang, Explicit solutions of a certain class differential equations by means of fractional calculus, Russian $J$. Math. Phys., 14 (2007), 357-365.

[54] H. M. Srivastava and H. L. Manocha, A Treatise on Generating Functions, Halsted Press (Ellis Horwood Limited, Chichester), John Wiley and Sons, New York, Chichester, Brisbane, and Toronto, 1984.

[55] H. M. Srivastava and S. Owa (Editors), Univalent Functions, Fractional Calculus, and Their Applications, Halsted Press (Ellis Horwood Limited, Chichester), John Wiley and Sons, New York, Chichester, Brisbane and Toronto, 1989.

[56] H. M. Srivastava and S. Owa (Editors), Current Topics in Analytic Function Theory, World Scientific Publishing Company, Singapore, New Jersey, London and Hong Kong, 1992.

[57] H. M. Srivastava, S. Owa and K. Nishimoto, Some fractional differintegral equations, J. Math. Anal. Appl., 106 (1985), 360-366.

[58] F. G. Tricomi, Funzioni Ipergeometriche Confluenti, Edizioni Cremonese, Rome, 1954.

[59] S.-T. Tu, D.-K. Chyan and H. M. Srivastava, Some families of ordinary and partial fractional differintegral equations, Integral Transform. Spec. Funct., 11 (2001), 291-302.

[60] S.-T. Tu, Y.-T. Huang, I-C. Chen and H. M. Srivastava, A certain family of fractional differintegral equations, Taiwanese J. Math., 4 (2000), 417-426.

[61] S.-T. Tu, S.-D. Lin, Y.-T. Huang and H. M. Srivastava, Solutions of a certain class of fractional differintegral equations, Appl. Math. Lett., 14 (2) (2001), 223-229.

[62] S.-T. Tu, S.-D. Lin and H. M. Srivastava, Solutions of a class of ordinary and partial differential equations via fractional calculus, J. Fract. Calc., 18 (2000), 103 110.

[63] P.-Y. Wang, S.-D. Lin and H. M. Srivastava, Explicit solutions of Jacobi and Gauss differential equations by means of operators of fractional calculus, Appl. Math. Comput., 199 (2008), 760-769.

[64] P.-Y. Wang, S.-D. Lin and S.-T. Tu, A survey of fractional-calculus approaches the solutions of the Bessel differential equation of general order, Appl. Math. Comput., 187 (2007), 544-555.

[65] G. N. Watson, A Treatise on the Theory of Bessel Functions, Second edition, Cambridge University Press, Cambridge, London and New York, 1944. 
[66] E. T. Whittaker and G. N. Watson, A Course of Modern Analysis : An Introduction to the General Theory of Infinite Processes and of Analytic Functions, With an Account of the Principal Transcendental Functions, Fourth edition, Cambridge University Press, Cambridge, London and New York, 1927.

$$
\text { Р е } з \text { и м е }
$$

\section{ЕЛЕМЕНТАРЕН И ВОВЕДЕН ПРИСТАП КОН ФРАКТАЛНО ИНФИНИТЕЗИМАЛНО СМЕТАҢЕ (ФРАКЦИОНАЛЕН КАЛКУЛУС) И НЕГОВИТЕ ПРИМЕНИ}

Предметот на фракционално инфинитезимално сметање (фракционален калкулус) (т.е. сметање на интеграли и изводи од произволен реален или комплексен ред) се здоби со значителна популарност и значајност во последните три декади, најмногу поради демонстрираните примени на овој метод во бројни навидум сосем различни и широки полиња на науката и инженерството. Тој навистина обезбедува неколку потенцијално корисни алатки за решавање на диференцијални и интегрални равенки и различни други проблеми кои вклучуваат специјални функции од математичката физика, како и нивните проширувања и генерализации од една и повеќе променливи. Главна цел на овој труд е да се презентира кус елементарен и воведен пристап кон теоријата на фракционо инфинитезимално сметање и неговите примени, особено при развивање на решенија на одделни интересни семејства на обични и парцијални фракциони интегродиференцијални равенки. Исто така, ќе бидат индицирани релевантни врски на некои од резултатите презентирани во овој труд со оние добиени во повеќе поранешни трудови од оваа област.

Клучни зборови: фракционално инфинитезимално сметање; диференцијални равенки; интегрални равенки; интегродиференцијални равенки; специјални функции; математичка физика; Fuchsian- и не-Fuchsian диференцијални равенки

\section{Adress:}

Hari M. Srivastava

Department of Mathematics and Statistics, University of Victoria, British Columbia V8W 3R4, Canada

harimsri@math.uvic.ca

Web Site: http://www.math.uvic.ca/faculty/harimsri/

Accepted: 12. IX 2008

\footnotetext{
Оваа статија е базирана на воведното предавање на проф. Сривастава при изборот за член надвор од работниот состав на Македонската академија на науките и уметностите.
}

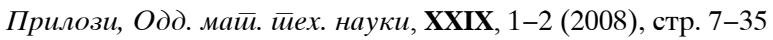

